\title{
Diabetic Nephropathy Progression in type 1 Diabetes: Temporal Renal Angiopoietin-Like Protein 2-Toll-Like Receptor 4 and Role of Early Renal Angiotensin II Inhibition by Valsartan
}

\section{Mona K. Tawfik}

Suez Canal University Faculty of Medicine

mohammed keshawy ( $\nabla$ mmkeshawy@yahoo.com )

Suez Canal University Faculty of Medicine https://orcid.org/0000-0001-8080-513X

\section{Samy Makary}

Suez Canal University Faculty of Medicine

\section{Research Article}

Keywords: Nephropathy, ANG II, ANGPTL2, TLR4, nephrin, valsartan

Posted Date: March 10th, 2021

DOl: https://doi.org/10.21203/rs.3.rs-256235/v1

License: () (i) This work is licensed under a Creative Commons Attribution 4.0 International License.

Read Full License 


\section{Abstract}

Diabetic nephropathy (DN) is a consequence of diabetes mellitus (DM). DM is associated temporal changes in renal angiotensin II (ANG II) release and multiple mediators leading to DN. These changes were evaluated using early ANG II blocker valsartan as a DN renoprotective drug. Adult male Wister rats were divided into (i) vehicle group; (ii) valsartan received oral $30 \mathrm{mg} / \mathrm{Kg} /$ day; (iii) diabetic received single $50 \mathrm{mg} / \mathrm{Kg}$ intraperitoneal streptozotocin injection; (iv) renoprotection, valsartan treated-diabetic rats after 7 days from DM. Other group of diabetic animals assigned to receive late valsartan intervention from week 9 to 12 of DM. The renoprotective effect evaluated at $4^{\text {th }}, 8^{\text {th }}, 12^{\text {th }}$ weeks. DN effects on urine albumin excretion, blood pressure and renal ANG II were measured. Urinary nephrin and kidney injury molecule-1 biomarkers, renal ANGPTL2, and toll-like receptor 4 (TLR 4) mRNA expression were tested. DNinitiated fibrotic markers integrin, a-smooth muscle expression and collagen IV and apoptotic protein caspase 3 were tested. DM induced changes starting from the $4^{\text {th }}$ week. At $12^{\text {th }}$ week, early valsartan intervention showed a significant reduction in ANG II, ANGPTL2 and TLR 4 expression and improvement in albuminuria, blood pressure, urinary biomarkers, fibrotic and apoptotic markers, more than the late intervention. Early inhibition of ANG II in diabetes is associated with decrease in ANGPTL2 and TLR 4 proteins and fibrotic changes. This observation helps in understanding DN pathophysiology and its therapeutic approaches.

\section{Introduction}

Diabetes mellitus (DM) has significant morbidity on patients; in which uncontrolled hyperglycemia induces diabetic nephropathy (DN) [1], renal fibrosis and end-stage renal disease (ESRD) [2]. Diabetes is associated with metabolic and hemodynamic alterations contributing to DN [3].

Hyperglycemia induces early glomerular hyperfiltration $[4,5]$, which occurs early in diabetes due to proximal tubular reabsorption of sodium chloride, leading to a reduction in sodium chloride reaching the macula densa and consequently release of renin and local production of angiotensin II (ANG II) [2, 4-6]. Hyperglycemia induces efferent arteriole constriction leading to intraglomerular hypertension with dysfunctional nephron injury[7].

Hyperglycemia-induced nephron dysfunction leads to inflammatory cytokines injury to podocytes and promote their apoptosis [2] which can be detected by nephrin, a podocyte marker [8, 9]. DN is correlated with albuminuria and kidney injury molecule-1 (KIM-1) [10] and inflammatory markers as nuclear factor kappa-light-chain-enhancer of activated B cells (NF-KB) [3, 11]. Activation of NF-KB is associated with renal transforming growth factor-beta 1 (TGF- $\beta 1$ ) and collagen IV; leading to activation of toll-like receptor 4 (TLR4), extracellular matrix accumulation and fibrosis $[2,11,12]$. Hyperglycemia and ANG II-induced NF$\mathrm{KB}$ activation with subsequent TLR4 expression modulate immune responses and the inflammatory cytokines release in DN $[13,14]$. Diabetes-induced inflammatory processes is associated with integrin and alpha smooth muscle expression and glomerulosclerosis $[15,16]$. Blocking ANG II showed to reduce DN 
progression [17-19]. Valsartan blocks ANG II by antagonizing angiotensin subtype 1 (AT 1) receptor and relieve vasoconstriction $[20,21]$.

Angiopoietin-like protein 2 (ANGPTL2) is vascular growth factors with proinflammatory properties promoting vascular destabilization in diabetes [22]. In vitro, in hyperglycemia knockdown ANGPTL2 decreased collagen IV and fibrosis [23]. In vivo, ANGPTL2 knockdown ameliorated DN by inhibiting TLR4 expression [24]. Streptozotocin (STZ) injected rats, ANGPTL2 begins to increase with the disease progression, microalbuminuria denoting endothelial injury [21, 22, 25]. However, in DN ANG II blocker effect on ANGPTL2 is not clear yet.

Clinical trials have so far shown inconsistent results for using angiotensin blockade to decrease the risk of progression to microalbuminuria in normotensive patients [26, 27]. Clinical studies start when the disease is already started $[28,29]$ or with established DN[30] as therapeutic tool. Experimentally, valsartan administration could started after 8 weeks of diabetes and shows therapeutic effect[15]. Also experimentally, inhibiting ANG II early from 0 to 4 weeks post diabetes prevented early diabetic glomerular hypertension and ameliorated glomerulosclerosis (GS)[17, 18]. Hyperglycemia induces multiple factors leading to DN. DN-associated remodeling leads to renal structural changes via subcellular signaling pathways[31]. Therefore, the present study exploited the temporal progression of DN and the role of ANG II blocker, valsartan, on renal ANG II, ANGPTL2, TLR4, NF-KB and inflammatory cytokines on the progression of $\mathrm{DN}$, fibrosis and albuminuria. This will differentially explore the role of these factors that contribute to deleterious mechanisms in the nature history of the disease and the therapeutic benefits of valsartan.

\section{Materials And Methods}

\subsection{Experimental animal procedures}

This study was carried using 20 weeks adult male Wister rats weighing $300 \pm 30 \mathrm{~g}$. The animal's care and handling were done in agreement with the guidelines of the National Institutes of Health $(\mathrm{NIH})$, the Guide for the Care and Use of Laboratory Animals from the Institute for Laboratory Animal Research, National Research Council, Washington, D.C., and the Suez Canal University, faculty of medicine animal care committee (Research \#4302).

Animals were housed with free access to standard rat chow and water ad libitum and kept at a constant 12-hour light/dark cycle, room temperature and humidity. Animals were left for acclimatization for seven days before the start of experiments [32].

\subsection{Drugs and chemicals}

STZ was purchased from Sigma-Aldrich (MO, USA) and was prepared by dissolving in $0.1 \mathrm{M}$ citrate buffer $(\mathrm{pH}=4.5)$. Valsartan $(30 \mathrm{mg} / \mathrm{kg} /$ day $)$ [12] was provided from Novartis Chemical Co., Egypt as white powder which dissolved and given once daily by gastric tube. Flexible tube was used to decrease oesophageal trauma. The tube is gently inserted in the animal mouth and passed down to the stomach 
without resistance. The dissolved drug was administered slowly to avoid stomach reflux. Observation to any signs of respiratory distress during the procedure was mandatory. The tube was then withdrawn slowly. The animals were observed for a while for any immediate adverse effect before returned to a holding cage.

\subsection{Induction of T1D in rats}

Rats were fasted overnight after which they got a single intraperitoneal injection (i.p.) of STZ (50 mg/ $\mathrm{kg}$ ) [33]. Sucrose ( $15 \mathrm{~g} / \mathrm{L})$ was added to the drinking water for $48 \mathrm{~h}$ to limit early mortality from the released insulin from the damaged pancreatic islets[34] and blood sugar monitored closely to avoid fatal hypoglycemia. To detect the successful animal model, after one-week, fasting blood glucose level[35] was measured using one Touch Ultra Mini glucometer (USA). Rats with fasting blood glucose of over 280 $\mathrm{mg} / \mathrm{dL}$ were included in the study[34]. To prevent subsequent development of ketonuria and breakdown of body fat, diabetic rats received daily subcutaneous insulin of dual-acting insulin (Mixtard, $0.5 \mathrm{IU} / \mathrm{Kg}$ ) (Novo Nordisk, Egypt) to maintain the blood glucose levels $>300 \mathrm{mg} / \mathrm{dl}$ and prevent rat death induced by excessively high blood glucose levels [34, 36, 37 ].

\subsection{Study Protocol}

Rats were assigned into different durations of the early valsartan protective effect, renoprotecive (Fig. 1, $A, B, C)$ to test the duration effect of valsartan $(4,8,12$ weeks), and renotherapeutic, testing late valsartan effect after DM development from week 9 to 12 of diabetes induction (Fig. 1, supplementary), in STZinduced DN. The renoprotective effect was assessed by allocating the rats into four groups. Group 1: vehicle control group: normal rats injected with single i.p. injection of citrate buffer, then treated with normal oral saline from the 2 nd week. Group 2: valsartan control group: normal rats injected with single i.p. injection of citrate buffer, then treated with valsartan from the beginning of 2 nd week. Group 3: diabetic control group: normal rats injected with single i.p. injection of STZ, then treated with normal saline from the 2 nd week. Group 4: valsartan treated group: diabetic rats treated with valsartan from the beginning of the 2 nd week. For, the renotherapeutic effect, valsartan effect tested from the beginning of the 9th week to 12th week of diabetes (Fig. 1, Fig. 1 supplementary).

\subsubsection{Experiments}

Early, valsartan administration began from the beginning of $2 \mathrm{nd}$ week, and rats were sacrificed after the end of the week 4, 8 and 12 of treatment (Fig. 1). Testing the renoprotective effect of valsartan in STZinduced DN was carried out on four groups (vechicle, valsartan control, diabetic control, valsartan treated) including three separate sets per group (4th, 8th, 12th weeks; $n=8 /$ set). Late valsartan administration were done on a separate diabetic animals which valsartan began from week 9-12 (Fig. 1, supplementary). Late valsartan treatment was considered as renotherapeutic to DN. All rats were sacrificed after the end of the 12th weeks

\subsubsection{Non-invasive blood pressure meaurement and urine samples collection}


To evalaute ANG II blocking effect in all groups using a BIOPAC non-invasive tail-cuff system (BIOPAC Systems, CA, USA) [12]. After a period of acclimatization of 14 days, systolic and diastolic blood pressure (SBP and DBP, respectvely) were mearsured by single trained personale away from any disturbing enivironment causing stress[38]. Urine samples were collected using the metabolic cages for 24 hours [39]

\subsubsection{Renal tissues and blood samples collection}

At experiments end, blood samples were collected via cardiac puncture [40] and centrifuged $(1600 \mathrm{~g}, 20$ $\min , 4^{\circ} \mathrm{C}$ ) for $10 \mathrm{~min}$ to obtain the serum and stored at $-80^{\circ} \mathrm{C}$ until use for various biochemical analyses, and then rats were sacrificed. Both kidneys were removed. The left kidney was immediately frozen at $-80^{\circ} \mathrm{C}$ for the different biochemical determinations, while the right one was processed to perform the histopathological and immunohistochemical assays.

\subsection{Biochemical analysis}

\subsubsection{Urine biochemical analysis: Determination of nephrin and KIM-1 levels}

Nephrin and KIM-1 levels as markers of glomerular filtration barrier integrity and renal injury were measured in urine using ELISA (BioSource Europe S.A., Brussels, Belgium) [10].

\subsubsection{Measurement of urine albumin excretion}

Twenty four hours urine albumin excretion (UAE) as a marker of DN was measured by using microalbumin kits strip (Nephelometry BN ProSpec, Siemens Health Care Diagnostic Products, Germany) [41].

\subsubsection{Renal NF-kB, ANGPTL2, integrin and TLR 4 mRNA expression by RT-PCR}

Renal NF-KB, ANGPTL2, and TLR 4 were assessed to determine DM inflammatory effect on the kidney $[42,43]$. Renal tissue was homogenized by SV total RNA isolation System (Promega, Madison, WI, USA) to extract RNA. Then, an ultraviolet spectrophotometer was used to measure RNA concentration and purity. We used $1 \mu \mathrm{g}$ extracted RNA to make cDNA using SuperScript III First-Strand Synthesis System (\#K1621, Fermentas, Waltham, MA, USA). Then, cDNA was amplified by real-time PCR (RT-PCR) and analyzed by Applied Biosystems software version 3.1 (StepOne ${ }^{\mathrm{TM}}$, USA). The PCR reaction used SYBR Green Master Mix (Applied Biosystems). Gene Runner Software (Hasting Software, Inc., Hasting, NY) was used in primers design using RNA sequences gene bank. RT-PCR amplification cycles were: 2 min at $50^{\circ}$, $10 \mathrm{~min}$ at $95^{\circ}$ and 15 seconds 40 cycles of denaturation and $10 \mathrm{~min}$ annealing/extension at $60^{\circ}$. RT-PCR data were estimated with the v1.7 sequencing program (PE Biosystems, Foster City, CA). Relative expression of studied gene mRNA was measured by the comparative $(\mathrm{Ct})$ method. Results were normalized to the $\beta$-actin which was used as the control housekeeping gene and reported as fold change over background levels detected in the studied groups. The gene-specific primer pairs for (NF-kB), forward 
primer 5'-CATTGAGGTGTATTTCACGG - 3, reverse primer 5'-GGCAAGTGGCCATTGTGTTC - 3. The (ANGPTL2) forward primer 5'-GGAGGTTGGACTGTCATCCAGAG-3', the reverse primer 5'-

GCCTTGGTTCGTCAGCCAGTA-3'. The (TLR 4)forward primer AATCCCTGCATAGAGGTACTTCCTAAT-3, the reverse primer CTCAGATCTAGGTTCTTGGTTGAATAAG-3. The integrin forward primer 5'-

AGGAGACTGAGAGCGAGCTG-3', the reverse primer 5'-TCAAAGCAGGCAAACAGATG-3'. The ( $\beta$-actin) forward primer 5'-TGTTTGAGACCTTCAACACC-3', the reverse primer 5'-CGCTCATTGCCGATAGTGAT-3'.

\subsubsection{Renal contents of IL-1 $\beta$, IL-6, TNFa, MCP-1 inflammatory levels using ELISA kits}

Renal tissue content of inflammatory cytokines produced during diabetes were estimated. Tissue samples were assessed for IL-1 $\beta$, IL-6, TNF-a, and MPC-1 concentrations using enzyme-linked immunosorbent assay (ELISA) kits (R\&D Systems, Minneapolis, Minnesota, USA) according to the manufacturer's instructions [35].

\subsubsection{Renal contents of angiotensin II, TGF- $\beta 1$ and collagen IV using ELISA kits}

Angiotensin II, TGF- $\beta$ and collagen IV contents were measured in renal homogenates by ELISA to detect the diabetic and ANG II blocking effect on renal tissue; using Cusabio rat ANG II, and the BioVendor rat TGF- $\beta 1$ and collagen IV [12].

\subsubsection{Determination of ASMA and collagen IV gene expression by western blot}

To further explore the diabetes-induced fibrotic activity renal a-Smooth muscle (ASMA) and collagen IV proteins were assessed to evaluate the renal reaction to angiotensin II blocking effect in the renoprotective and renotherapeutic experiments. extracted from tissue homogenates using ice-cold radioimmunoprecipitation assay (RIPA) and buffer supplemented kit, usingV3 Western Workflow ${ }^{\text {TM }}$ Complete System, Bio-Rad® Hercules, (CA, USA). The tissue buffer extraction was centrifuged at $4000 \times \mathrm{g}$ for $20 \mathrm{~min}$. Extracted protein was assessed using Bradford assay. Equal amounts of protein were loaded (20-30 $\mu \mathrm{g}$ of total protein) and separated by SDS/polyacrylamide gel electrophoresis ( $10 \%$ acrylamide gel) using a Bio-Rad Mini-Protein II system. Then, transferred to polyvinylidene difluoride membranes (Pierce, Rockford, IL, USA) with a Bio-Rad Trans-Blot system. The membrane was washed with PBS and blocked for $1 \mathrm{~h}$ at room temperature. After transfer, the membranes were washed with PBS and were blocked with $5 \%(\mathrm{w} / \mathrm{v})$ skimmed milk powder in PBS for $1 \mathrm{~h}$ at room temperature. Following blocking, the primary antibodies for ASMA and collagen IV and beta actin (Thermoscientific, Rockford, Illinois, USA) were incubated overnight at $\mathrm{pH} 7.6$ at $4^{\circ} \mathrm{C}$ with gentle shaking. Then the secondary antibodies were applied after washing the primary antibodies, and were incubated at $37^{\circ} \mathrm{C}$ for $1 \mathrm{~h}$. Band intensity was analyzed by ChemiDocTM imaging system with Image LabTM software version 5.1 (Bio-Rad Laboratories Inc., Hercules, CA, USA). The results were expressed as arbitrary units after normalization for $\beta$-actin protein expression[44]. 


\subsection{Renal histopathological examination}

Renal damage was evaluated and scored according to [45]. Tubular and interstitial changes including, desquamation and cytoplasmic changes examined by: H\&E: showed hydropic degeneration (swelling/vacuolization); PAS: showed brush border loss, hyaline globules, and peritubular\& interstitial inflammatory infiltration, Masson: showed interstitial fibrosis and interstitial vascular wall thickening or congestion. Sections were examined blindly and randomly in 5 locations. To accurately compare and analyze the damage a graded score was followed: 0: (normal), 1: mild, 2: moderate, and 3: severe, where minimum score 0 , and maximum score of 15 [max. score 3 in 5 locations]. Glomerulo-sclerotic injury was semi-quantitatively graded as follows:0: intact glomeruli (normal), 1 : lesions affecting $\leq 25 \%$ of the glomerular area (mild sclerosis),2: lesions affecting $25-50 \%$ of the glomerular area (moderate sclerosis), and 3: lesions affecting $\geq 75 \%$ of the glomerular area (severe sclerosis). Renal damage was calculated as the sum of both tubular and glomerular damage[36].

\subsection{Renal Immunohistochemistry and image analysis}

Renal tissue specimens were deparaffinized, rehydrated and prepared for immunohistochemical staining. Rat monoclonal antibodies against apoptotic markers (caspase-3) (Abcam, Cambridge, UK) was used. Then slides were examined using a light microscope (Olympus cx21, Japan). The percentage of immunopositive areas was determined using Image J 1.45 F (National Institute of Health, USA) [43].

\subsection{Statistical Analysis:}

Results were expressed as Mean \pm SD using statistical software for the social sciences (SPSS), version 17. The difference between variables was analysed using one-way analysis of variance (ANOVA) for quantitative variables and Kruskal-Wallis for parameters with non-Gaussian distribution, followed by Tukey's post-hoc test for multiple comparisons. Unpaired Student's T-test was used to compare two individual groups. The difference was considered significant when $\mathrm{P}$ value $<0.05$.

\section{Results}

\subsection{Pattern of urine albumin excretion response to valsartan in STZ-induced diabetic nephropathy:} Renoprotective versus renotherapeutic effect

To evaluate the establishment of the DN rat model, the UAE was assessed and showed albuminuria in diabetic rats (Table 1) which proves the establishment of the model. Suppressing ANG II in diabetic rats effect on UAE was assessed to determine the renoprotection and renotherapeutic (Table 1, Table 1 supplementary) effect of valsartan on DN. Starting valsartan treatment at the beginning of the 2 nd week of diabetes to the 4th, 8th, 12th weeks prevented the chronological increment of UAE (normal $<30 \mathrm{mg} / 24$ hr) compared to non-treated diabetic animals $(p<0.05$, Table 1$)$. The diabetic valsartan-treated started at the beginning of the 9 th week, renotheraeutic groups, showed normalized UAE compared to diabetic group ( $p<0.05$, Tables 1 supplementary). 
Table 1

Urine albumin excretion response to valsartan in STZ- induced diabetic nephropathy

\begin{tabular}{|c|c|c|c|c|}
\hline & Vehicle & $\begin{array}{l}\text { Valsartan } \\
\text { control }\end{array}$ & $\begin{array}{l}\text { Diabetic } \\
\text { control }\end{array}$ & $\begin{array}{l}\text { Valsartan } \\
\text { treated }\end{array}$ \\
\hline UAE (mg /day), & $0.90 \pm 0.16$ & $0.94 \pm 0.12^{*}$ & $4.51 \pm 1.28^{4}$ & $2.45 \pm 1.03^{q^{\star}}$ \\
\hline Valsartan (Reno-protective) & $1.04 \pm 0.17$ & $0.91 \pm 0.15^{*}$ & $17.55 \pm 3.04^{\llbracket \#}$ & $4.50 \pm 1.25^{\star \star \#}$ \\
\hline $\begin{array}{l}\text { treatment to } \\
-4 \text { weeks }\end{array}$ & $0.99 \pm 0.12$ & $0.90 \pm 0.11^{*}$ & $31.73 \pm 3.27^{\mathbb{4} \# \$}$ & $7.15 \pm 1.18^{\mathbf{4} * \# \$}$ \\
\hline \multicolumn{5}{|l|}{-8 weeks } \\
\hline \multicolumn{5}{|l|}{-12 weeks } \\
\hline $\begin{array}{l}\text { UAE, urine albumin excretion } \\
\text { followed by Tukey's post-hoc } \\
\text { compared with vehicle group } \\
\text { compared with week } 4 \text {, \$ con }\end{array}$ & $\begin{array}{l}\text { lues are mear } \\
\text { t at } P<0.05 \text {. } \\
\text { ompared with } \\
\text { red with week }\end{array}$ & $\begin{array}{l} \pm S D(n=6-8) \\
\text { Isartan treatm } \\
\text { liabetic contro }\end{array}$ & $\begin{array}{l}\text { id analyzed usinc } \\
\text { t started at day } 7 \\
\text { roup at the same }\end{array}$ & $\begin{array}{l}\text { ne-way ANOVA } \\
\text { diabetes. } 9 \\
\text { ee point, \# }\end{array}$ \\
\hline
\end{tabular}

3.2. Pattern of blood pressure response to valsartan in STZ- induced diabetic nephropathy:

Renoprotective versus renotherapeutic effect

The effect of suppressing ANG II on BP was evaluated to assess the hemodynamic changes in treated and untreated diabetic rats (diabetic control group, Tables 2-3). Diabetic animals started valsartan at the beginning of 2nd week (valsartan treated group) did not show significant increase in SBP and DBP at the 12th week when compared to non-treated diabetic group (diabetic control group; $p<0.05$, Tables $2-3$ ). The diabetic valsartan-treated renotheraeutic groups showed normalized SBP and DBP compared to diabetic group ( $p<0.05$, Tables 1 supplementary). 
Table 2

Systolic blood pressure response to valsartan in STZ- induced diabetic nephropathy

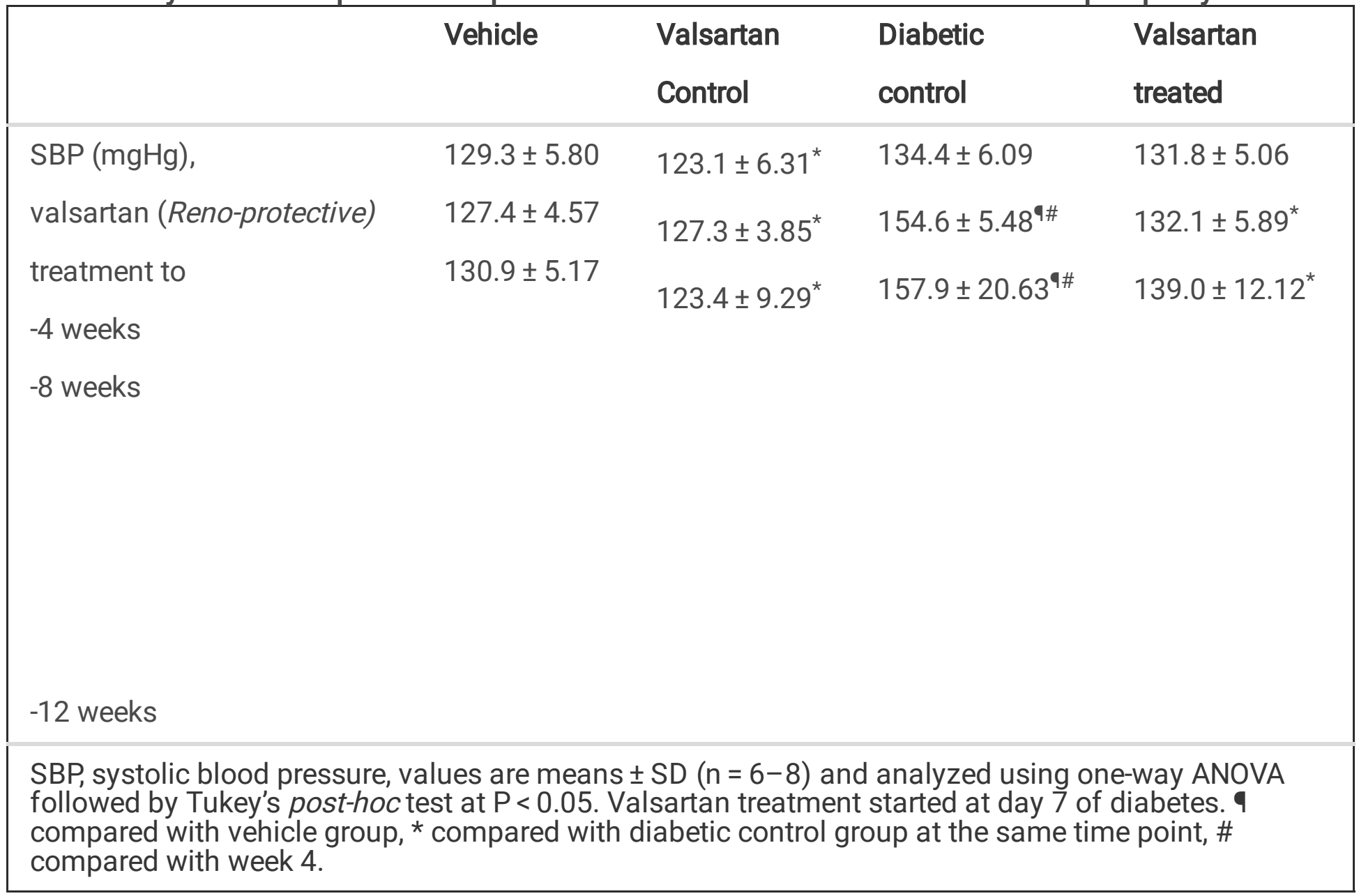

Table 3

Diastolic blood pressure response to valsartan on renal function in STZ- induced diabetic nephropathy

\begin{tabular}{|c|c|c|c|c|}
\hline & Vehicle & $\begin{array}{l}\text { Valsartan } \\
\text { Control }\end{array}$ & $\begin{array}{l}\text { Diabetic } \\
\text { control }\end{array}$ & $\begin{array}{l}\text { Valsartan } \\
\text { treated }\end{array}$ \\
\hline DBP (mgHg), & $80.9 \pm 11.56$ & $71.25 \pm 8.63^{*}$ & $86.50 \pm 7.82$ & $78.75 \pm 4.74$ \\
\hline Valsartan (Reno-protective) & $78.38 \pm 6.55$ & $69.25 \pm 6.41^{*}$ & $92.13 \pm 5.14^{9}$ & $78.63 \pm 9.18^{*}$ \\
\hline $\begin{array}{l}\text { treatment to } \\
-4 \text { weeks }\end{array}$ & $79.25 \pm 8.92$ & $70.63 \pm 7.25^{\star}$ & $98.50 \pm 3.34^{\natural \#}$ & $77.75 \pm 7.92^{*}$ \\
\hline \multicolumn{5}{|l|}{-8 weeks } \\
\hline \multicolumn{5}{|l|}{-12 weeks } \\
\hline $\begin{array}{l}\text { DBP, diastolic blood pressur } \\
\text { followed by Tukey's post-ho } \\
\text { compared with vehicle grou } \\
\text { compared with diabetic con }\end{array}$ & $\begin{array}{l}\text { ues are mean } \\
\text { at } P<0.05 . V \\
\text { ompared with } \\
\text { roup at week }\end{array}$ & $\begin{array}{l}\mathrm{SD}(\mathrm{n}=6-8) \text { ar } \\
\text { artan treatmen } \\
\text { betic control gi }\end{array}$ & $\begin{array}{l}\text { analyzed using } \\
\text { arted at day } 7 \text { o } \\
\text { ip at the same tir }\end{array}$ & $\begin{array}{l}\text {-way ANOVA } \\
\text { labetes. } 9 \\
\text { point, \# }\end{array}$ \\
\hline
\end{tabular}


3.3. Renoprotective and renotherapeutic effect pattern of valsartan on urinary nephrin and KIM-1 concentrations in STZ- induced diabetic nephropathy

The pattern of urinary nephrin and KIM-1 were used to assess the impact of ANG II suppression in diabetic treated and untreated animals. It was evident that the urinary concentration of both nephrin and KIM-1 were higher in the diabetic control group compared to the vehicle group, with a significant difference between their levels at the 12 th week and the 4 th and 8 th weeks $(p<0.05$, Fig. 2$)$. Treatment with valsartan reduced $(p<0.05)$ both nephrin and $\mathrm{KIM}-1$ concentrations in comparison with the diabetic control group. Implementing the valsartan "renoprotective" effect significantly attenuated KIM-1 concentration $(p<0.05)$ in comparison with the "renotherapeutic" regime (Fig. 2, supplementary).

3.4. Renoprotective and renotherapeutic effect pattern of valsartan on renal expression of $N F-K B$, ANGPTL2, TLR 4 and integrin in STZ- induced diabetic nephropathy

Then the pattern of ANGPTL2 as a marker of endothelial integrity, inflammatory marker, and the anchoring protein integrin response to valsartan was assessed in addition to inflammatory markers NFKB and TLR 4 (Fig. 3). STZ-induced DN was associated with an increase $(p<0.05)$ in mRNA expression of NF-KB, ANGPTL2, TLR 4 and integrin compared to the vehicle group, with a significant difference in NF-KB expression between the 4th and the 12 th weeks. The renotherapeutic regime resulted in downregulation of the high mRNA expression of these markers in comparison with the diabetic control group. Implementing the "renoprotective" regime significantly attenuated ANGPTL2, TLR 4 and integrin expression ( $p<0.05$ ) as compared to the the "renotherapeutic" one $(p<0.05$, Fig. 3-supplementary).

3.5. Renoprotective and renotherapeutic effect pattern of valsartan on renal expression of $I L-1 \beta, I L-6$, TNFa, MCP-1 inflammatory cytokines in STZ- induced diabetic nephropathy

The current study showed valsartan affecting NFKB expression which regulates inflammatory cytokine expression. Renal inflammatory cytokines were further examined using ELISA kit. The results in Table 4 show that IL-1 $\beta$, IL6, TFNa and MCP1 inflammatory cytokines increased significantly in the control diabetic group $(P<0.05)$ and early valsartan administration was able to inhibit these effects in the renoprotective regime compared to diabetic group (valsartan treated, $P<0.05$; Table 4 ). The decrease in the cytokines were not significant from the vehicle group. Late administration of valsartan in renothereapeutic regime, showed decrease of the renal inflammatory cytokines (supplementary Table 4). The decrease in IL-1 $\beta$, IL6, and MCP1 was significantly different from vehicle group $(P<0.05)$. An increasing trend of the cytokines in renotherepeutic compared with the renoprotective regime. 
Table 4

Renoprotective effect of valsartan by downregulating renal IL-1 $\beta$, IL-6, TNFa, MCP-1 inflammatory levels

\section{Vehicle Valsartan control Diabetic control Valsartan treated}

IL-1 $\beta$ (pg/mg protein)

Reno-protective $398.1 \pm 29.38 \quad 361.4 \pm 54.11 \quad 1473 \pm 172.50^{\natural} \quad 548.7 \pm 127.70^{* \#}$
IL-6 (pg/mg protein)

$\begin{array}{lllll}\text { Reno-protective } & 140.7 \pm 7.61 & 142.7 \pm 33.70 & 567.0 \pm 69.39^{9} & 208.9 \pm 53.65^{*}\end{array}$

$\mathrm{TNFa}(\mathrm{pg} / \mathrm{mg}$ protein)

Reno-protective $\quad 86.88 \pm 6.65 \quad 77.50 \pm 15.59 \quad 531.3 \pm 47.68^{\natural} \quad 166.8 \pm 61.03^{\text {*\# }}$

MCP-1 (pg/mg protein)

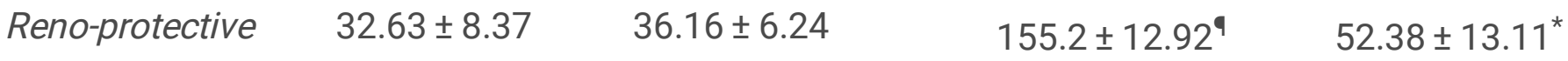

Interleukin (IL), Tumour Necrosis Factor alpha (TNFa), monocyte chemoattractant protein-1 (MPC-1). values are means $\pm S D(n=6-8)$ and analyzed using one-way ANOVA followed by Tukey's post-hoc test at $\mathrm{P}<0.05$. Comparison within the same group, ${ }^{9}$ compared with vehicle group, ${ }^{*}$ compared with diabetic control group," compared with valsartan group.

3.6. Renoprotective and renotherapeutic effect pattern of valsartan on renal content of angiotensin II, TGF- $\beta$ and collagen IV in STZ- induced diabetic nephropathy

Renal ANG II and profibrotic markers, TGF- $\beta$ and collagen IV, were assessed to explore the pattern valsartan effect over time (Fig. 4). The results showed that the mean renal ANG II, TGF- $\beta$ and collagen IV in the diabetic control group were higher $(p<0.05)$ than that in the vehicle group. It was obvious that TGF$\beta$ and collagen IV contents were higher $(p<0.05)$ during the course of diabetic nephropathy with a significant $(p<0.05)$ difference in their levels at different time points. The implemented angiotensin II blockade reduced these parameters in comparison with the diabetic control group. Valsartan "renoprotective" treated group at 12th week displayed a decline in the high concentrations of these markers in diabetic control group as compared with the valsartan "renotherapeutic" treated group $(p<$ 0.05, Fig. 4-supplementary).

3.7. Renoprotective and renotherapeutic effect of valsartan on the relative renal expression of ASMA and Collagen IV in STZ-induced diabetic nephropathy

Diabetic groups received the renoprotective regime showed less ANGPTL2, inflammatory, proliferative and DN features as compared to renothereapeutic regime (Figs. 2, 3, 4 supplementary). Therefore, Fig. 5 illustrates the comparison between the two regimes regarding the alpha-smooth muscle actin, ASMA, as a marker of cellular proliferation and collagen IV expression, as a marker of increased mesangial matrix and glomerular injury. Diabetes enhanced significantly both marker expression $(P<0.05)$ in comparison 
to normal rats. It was evident that valsartan "renoprotective" treated group displayed a significant reduction in the relative expression of ASMA and collagen IV as compared to the valsartan "renotherapeutic" treated group ( $p<0.05$, Fig. 5).

3.8. Renoprotective and renotherapeutic effect pattern of valsartan on the renal histopathological picture in STZ-induced diabetic nephropathy

Then, renal tissues were examined to detect the chronological pattern of fibrotic changes associated with DN in renoprotective and renotherepeutic regimes using H\&E, Masson and PAS staining. The histopathological examination of renal tissues revealed that the vehicle group showed preservation of the normal architecture of renal glomeruli and tubules. However, kidney tissues in the diabetic control group exhibited increment pattern of pathological changes (4th, 8th, 12th week) with different extent at different time points in the term of interstitial inflammatory infiltrate with congested thick-walled vessels. The tubular epithelial cells showed desquamation and hydropic degeneration with focal sclerosis in the glomeruli. Masson showed interstitial and peritubular fibrosis (stained blue) and PAS showed thickening of basement membrane with loss of brush border and vacuolation (Figs. 6,7-I). It was evident that diabetes was associated with an increase in the mean histopathological score in renal tissues in both renouprotective and renotherepeutic regimes compared to the vehicle group $(p<0.05$, Figs. 6,7-II), with a significant difference between its score in the 12th week and the 4th and 8th weeks (Fig. 7-II).

In both renouprotective and renotherepeutic regimes (Figs. 6,7-I), it was evident that valsartan treatment duration showed chronological effectiveness with varying degrees in ameliorating the mean histopathological score in comparison with the diabetic control group $(p<0.05$; Figs. $6,7-1 I)$. Notably, the renoprotective role of valsartan was more prominent in attenuating the severity of diabetic nephropathy and improving the renal histopathological score compared to valsartan "renotherapeutic" treated group $(p<0.05$; Fig. 7-II).

3.9. Reno-protective and reno-therapeutic effect pattern of valsartan on the apoptotic marker (caspase-3) immunostaining in STZ- induced diabetic nephropathy

Figure 8 highlighted the pattern of DN-associated apoptosis $(p<0.05)$ in diabetic renal tissues as revealed by the elevated pro-apoptotic activators "caspase-3" percentage compared to vehicle group with a significant difference between its level in the 8th and 12th weeks in comparison with the 4th week $(p<$ 0.05 , Fig. 8). It was apparent that valsartan inhibits apoptosis, as evidenced by the reduction in the proapoptotic caspase-3 compared to the diabetic control group (Fig. 8). However, valsartan "renoprotective" treated group at 12th week displayed a significant reduction in the pro-apoptotic activators as compared to the valsartan "renotherapeutic" treated group $(p<0.05$, Fig. 8-II).

\section{Discussion}

The current study findings highlighted the temporal pattern of ANG II inhibitor (valsartan) in preventing diabetes-induced angiotensin vasoconstrictor effect on renal arterioles [17] and improving the associated 
increase of UAE, ANGPTL2, TLR4, integrin, NF-KB, inflammatory cytokines, TGF- $\beta 1$ and GS $[23,24,46]$. Chronic kidney disease endpoint is fibrosis which is associated with high ANGPTL2-TGF- $\beta 1$-integrin expression[47, 48]. Integrin is a cell-matrix interactions protein activates intracellular signalling[49]. ANGPTL2 increases TGF- $\beta 1$ expression through integrin-mediated activation[48] leading to renal fibrosis[47]. Diabetes enhanced renal TGF- $\beta 1$, integrin kinase and ASMA expression which is under ANG II regulation[50] as observed in this study. Therefore, decreasing the early diabetes-induced hyperfiltrationinduced renal hypertension[5] effect is the cornerstone in improving its consequences on renal functional deterioration, inflammation, angiogenesis and fibrosis[51]. The consensus of previous studies comes in agreement with the current study findings regarding the protective and therapeutic effect of valsartan by disrupting diabetes-induced local ANG II release in DN. However, this study showed the chronological pattern of blocking ANG II effect on mitigating DN-associated cofactors.

DN has early glomerular barrier and tubular dysfunction component [4, 52]. Early in diabetes, the hemodynamic changes involve efferent arteriolar vasoconstriction in contrast to afferent vasodilation that ultimately increases glomerular hydrostatic pressure [17], leading to glomerular hyperfiltration in diabetes[53]. Afferent arteriolar dilation per se and subsequent glomerular capillary hypertension lead to proteinuria independent of systemic arterial pressure [7]. Throughout the study period from the 4th -12th weeks post STZ, the study findings showed the influence of ANG II inhibition on decreasing UAE as features of DN[54]. The DN model shares the significant hallmarks of most forms of kidney injury seen in humans, developing hypertension and proteinuria $[8,54]$ which were observed in the current study. Diabetes increases glomerular capillary hydrostatic pressure and systemic pressure, and both contribute to glomerular protein loss [1]. The increase in blood pressure was observed in STZ -injected rats from the 2-7 weeks [55], which was due to the increase vasopressors in rats injected with the same STZ dose (50 $\mathrm{mg} / \mathrm{Kg}$ ) as used in the current study. The high plasma glucose level increases blood osmolarity inducing osmoreceptor vasopressin release [56]. A modest increase in systemic blood pressure results in vasodilated preglomerular microvasculature which is transmitted to the glomerulus with exacerbation of glomerulosclerosis processes[53]. Therefore, reductions in systemic arterial and glomerular pressures by valsartan reduced the glomerular damage in DM.

Urinary nephrin assesses the kidney's podocyte proteins that reflect the filtration barrier integrity[9]. Diabetes-induced ANG II promotes podocyte injury and promotes the progression to DN via persistent activation of Notch1 and Snail signalling in podocytes, and eventually down-regulation of nephrin expression [57]. Transient increase in nephrin expression occurs in the first eight weeks [58]as observed in the current study. Valsartan showed to ameliorate DN by increasing glomerular nephrin expressions and consequently lowering urinary albumin, collagen type IV, and improved renal function [15]. Urinary KIM-1 and nephrin as early DN markers were also proven to increase with the progression of the disease [10, 15]. The current results showed improvement of DN markers from progression as the therapeutic effect of ANG II blockade by valsartan. Early inhibition of renal ANG II halts the progression of DN which is an essential step in the pathophysiology and treatment of DN[59]. 
In STZ injected rats, antagonizing AT1 receptor by valsartan attenuated renal ANG II and other cytokines which modulated the diabetes-associated hemodynamic changes and DN[21]. Whole glomeruli or glomerular endothelial cells showed a persistent increase in ANGPTL2 expression at the 4th week of the STZ injected rats [22]; and human patients[42] indicative of disrupting renal vascular integrity. In patients with T1D, serum ANGPTL2 showed a higher level than nondiabetic and associated with microalbuminuria. Consequently, blocking the ANG II pathway in the current study resulted in preservation of endothelial integrity and pointed to the initiation of disturbed angiogenesis and vascular inflammationinduced DN[25]. Therefore, it is good reno-therapeutic treatment in DN as the current results showed.

Persistent hyperglycemia and ANG II activate renal NFKB and trigger inflammatory cytokines and profibrotic factors [11]. In diabetic animals, blocking ANG II by valsartan attenuated the NFKB and the inflammatory pathway [12] leading to $D N$, as the current results show valsartan as a renal therapeutic and protective agent. NFKB was proven to be associated with renal macrophage infiltration as a response to hyperglycaemia[14]. The downstream of NF-KB signalling of inflammatory cytokines were investigated in diabetic animals in the present study and increase in IL-1 $\beta$, IL-6, TNFa, MCP-1 inflammatory cytokines were detected as previously reported[24] that was ameliorated by valsartan. Knocking down ANGRTL2 resulted in decrease TLR4 and consequently inflammatory cytokines level [24]. TLR4, an immune modulator [43], expression in renal tissue increased with DN and correlated with macrophage infiltration, poor glycaemic control and deterioration of renal function in diabetic patients[14]. Activated TLR4 receptor initiates NFKB which in turn induces multiple various pro-inflammatory cytokines participates in diabetes-induced inflammatory response and apoptosis leading to DN $[43,60]$. Previous study also showed that ANG II induces TLR4 expression in renal tissue[13]. In the current study, results showed increased expression of TLR4 as well as NFKB which were attenuated by valsartan administered early in the disease which confirms their implication in the DN pathophysiology. Valsartan administration late in the disease improved both markers which show its therapeutic role in decreasing DN processes by lowering the expression of these two inflammatory markers. It also improved the histopathological score and apoptosis (Caspase-3) either administered early or late in the disease. Hyperglycaemia-induced NFKB activation induces inflammatory, TNFa and IL-1 $\beta$, and oxidative stress, superoxide dismutase, release with the initiation of profibrotic markers TGF- $\beta 1$ and collagen IV in diabetic animals as observed in the current study[12, 61]. Thus, the role of ANG II with TLR4 and NFKB are associated with downstream DN proinflammatory and apoptotic sequences. Thus, rregulation of intrarenal ANG II activation is essential in developing DN and its control improves the fate of DN patients.

\section{Clinical consideration}

The present study demonstrates long-term ARB inhibition in an animal model of T1D, which can delay and decrease the development of diabetic glomerulopathy, by modulating glomerular diabetes-associated hemodynamic changes. Further studies are needed to weight hemodynamic versus non-hemodynamic $[12,52]$ factors that predominate in the pathophysiology and pathogenesis of $D N$ in clinical practice and the starting time of ARB initiation. 


\section{Potential Limitations}

The successful time point of ANG II inhibition of ANGPTL2/TLR4 [24] will require further investigation. DN will eventually end up by fibrosis due to ANGPTL2/TGF- $\beta 1 /$ integrin activation $[47,48]$. However, it remains to be determined whether ANG II inhibition affect which part of the nephron, the interstitium and interstitial macrophages or podocyte, to stop the fibrotic cascade $[24,42,48]$.

In the present study, ANG II inhibition was associated with decrease ANGPTL2 expression that was tested in vivo conditions that are different from those in vitro. Cultured 3-day-old Wistar rat cardiomyocytes shown that ANG II suppresses ANGPTL2 expression whereas ARB could significantly reverse this decrease by inhibiting AT1 receptor [62]. The authors argued that ANG II could enhance ANGPTL2 expression or be without effect due to the difference in the used techniques, various exposure times and concentrations. Therefore, isolated renal tissues need further investigation to study subcellular molecular localization under ANG II inhibition during the DN progression.

\section{Conclusion}

These results suggest that early inhibition (renoprotective) of ARB (valsartan) is better than late (renotherapeutic) that affect the initiation or progression of DN by blood glucose-independent mechanisms. Early inhibition of ANG II in diabetes showed to decrease renal injury tested by decrease urinary nephrin and KIM-1. The decrease in renal ANG II is accompanied by decrease in ANGPTL2, TLR4, ASMA, integrin expression and inflammatory state leading to fibrosis and renal injury as indicated by decrease in UAE and BP.

\section{Declarations}

\section{Conflict of interest}

The authors declare that there are no conflicts of interest associated with this study

Funding : This research did not receive any specific grant from funding agencies.

\section{Acknowledgments}

The authors thank Prof Laila Rashed, Biochemistry Department, Faculty of Medicine, Kasr Aini University. We also give our thanks to Dr. Mohamed K. El-Kherbetawy, Pathology Department, Faculty of Medicine, Suez Canal University.

Ethics approval: Suez Canal University, faculty of medicine animal care committee (Research No. 4302).

Conflicts of interest: There is no conflict of interest

Funding : No funding agencies contributed in this work 
Consent for participation: All authors had participated and approved this work.

Consent for publication: All authors had approved the manuscript and agreed for publication in molecular biology reports.

\section{Author contribution:}

Mona K. Tawfik: Conceptualization, Data curation, Formal analysis, Investigation, Methodology. Project administration, Resources, Supervision, Validation, Visualization, Writing - original draft, Writing review \& editing

Mohammed M. Keshawy: Conceptualization, Resources, Validation, Visualization, Writing - original draft, Writing - review \& editing scientific writing

Samy Makary: Conceptualization, Data curation, Formal analysis, Investigation, Methodology , Validation , Visualization, Writing - original draft, Writing - review \& editing scientific writing

Availability of data and material: all data are presented in this work.

Code availability : not applicable

\section{References}

1. Palatini P (2012) Glomerular hyperfiltration: a marker of early renal damage in pre-diabetes and prehypertension. Nephrol Dial Transplant 27:1708-14. doi: 10.1093/ndt/gfs037

2. Lin YC, Chang YH, Yang SY, Wu KD and Chu TS (2018) Update of pathophysiology and management of diabetic kidney disease. J Formos Med Assoc 117:662-675. doi: 10.1016/j.jfma.2018.02.007

3. Cao Z and Cooper ME (2011) Pathogenesis of diabetic nephropathy. J Diabetes Investig 2:243-7. doi: 10.1111/j.2040-1124.2011.00131.x

4. Patinha D, Fasching A, Pinho D, Albino-Teixeira A, Morato M and Palm F (2013) Angiotensin II contributes to glomerular hyperfiltration in diabetic rats independently of adenosine type I receptors. Am J Physiol Renal Physiol 304:F614-22. doi: 10.1152/ajprenal.00285.2012

5. Tuttle KR (2017) Back to the Future: Glomerular Hyperfiltration and the Diabetic Kidney. Diabetes 66:14-16. doi: $10.2337 / \mathrm{dbi16-0056}$

6. Giani JF, Janjulia T, Taylor B, Bernstein EA, Shah K, Shen XZ, McDonough AA, Bernstein KE and Gonzalez-Villalobos RA (2014) Renal generation of angiotensin II and the pathogenesis of hypertension. Curr Hypertens Rep 16:477. doi: 10.1007/s11906-014-0477-1

7. Park S, Bivona BJ, Feng Y, Lazartigues E and Harrison-Bernard LM (2008) Intact renal afferent arteriolar autoregulatory responsiveness in db/db mice. Am J Physiol Renal Physiol 295:F1504-11. doi: 10.1152/ajprenal.90417.2008 
8. Kandasamy Y, Smith R, Lumbers ER and Rudd D (2014) Nephrin - a biomarker of early glomerular injury. Biomark Res 2:21. doi: 10.1186/2050-7771-2-21

9. Akankwasa G, Jianhua L, Guixue C, Changjuan A and Xiaosong Q (2018) Urine markers of podocyte dysfunction: a review of podocalyxin and nephrin in selected glomerular diseases. Biomark Med 12:927-935. doi: 10.2217/bmm-2018-0152

10. Peterson RG, Jackson CV and Zimmerman KM (2017) The ZDSD rat: a novel model of diabetic nephropathy. Am J Transl Res 9:4236-4249.

11. Suryavanshi SV and Kulkarni YA (2017) NF-kappabeta: A Potential Target in the Management of Vascular Complications of Diabetes. Front Pharmacol 8:798. doi: 10.3389/fphar.2017.00798

12. Makary S, Abdo M, Hassan WA and Tawfik MK (2019) Angiotensin blockade attenuates diabetic nephropathy in hypogonadal adult male rats. Can J Physiol Pharmacol 97:708-720. doi: 10.1139/cjpp-2018-0572

13. Lv J, Jia R, Yang D, Zhu J and Ding G (2009) Candesartan attenuates Angiotensin Il-induced mesangial cell apoptosis via TLR4/MyD88 pathway. Biochem Biophys Res Commun 380:81-6. doi: 10.1016/j.bbrc.2009.01.035

14. Lin M, Yiu WH, Wu HJ, Chan LY, Leung JC, Au WS, Chan KW, Lai KN and Tang SC (2012) Toll-like receptor 4 promotes tubular inflammation in diabetic nephropathy. J Am Soc Nephrol 23:86-102. doi: 10.1681/ASN.2010111210

15. Sanajou D, Ghorbani Haghjo A, Argani H, Roshangar L, Ahmad SNS, Jigheh ZA, Aslani S, Panah F, Rashedi $\mathrm{J}$ and Mesgari Abbasi M (2018) FPS-ZM1 and valsartan combination protects better against glomerular filtration barrier damage in streptozotocin-induced diabetic rats. J Physiol Biochem 74:467-478. doi: 10.1007/s13105-018-0640-2

16. Wen J, Ma Z, Livingston MJ, Zhang W, Yuan Y, Guo C, Liu Y, Fu P and Dong Z (2020) Decreased secretion and profibrotic activity of tubular exosomes in diabetic kidney disease. Am J Physiol Renal Physiol. doi: 10.1152/ajprenal.00292.2020

17. Zatz R, Dunn BR, Meyer TW, Anderson S, Rennke HG and Brenner BM (1986) Prevention of diabetic glomerulopathy by pharmacological amelioration of glomerular capillary hypertension. J Clin Invest 77:1925-30. doi: 10.1172/JCl112521

18. Anderson S, Rennke HG, Garcia DL and Brenner BM (1989) Short and long term effects of antihypertensive therapy in the diabetic rat. Kidney Int 36:526-36.

19. Lozano-Maneiro L and Puente-Garcia A (2015) Renin-Angiotensin-Aldosterone System Blockade in Diabetic Nephropathy. Present Evidences. J Clin Med 4:1908-37. doi: 10.3390/jcm4111908

20. Ruilope LM (2001) Valsartan and the kidney: review of preclinical and clinical data. Adv Ther 18:5766.

21. Rizkalla B, Forbes JM, Cao Z, Boner G and Cooper ME (2005) Temporal renal expression of angiogenic growth factors and their receptors in experimental diabetes: role of the renin-angiotensin system. J Hypertens 23:153-64. 
22. Gnudi L (2016) Angiopoietins and diabetic nephropathy. Diabetologia 59:1616-20. doi: 10.1007/s00125-016-3995-3

23. Huang $\mathrm{H}, \mathrm{Ni} \mathrm{H}, \mathrm{Ma} \mathrm{K}$ and Zou J (2019) ANGPTL2 regulates autophagy through the MEK/ERK/Nrf-1 pathway and affects the progression of renal fibrosis in diabetic nephropathy. Am J Transl Res 11:5472-5486.

24. Yang S, Zhang J, Wang S, Shi J and Zhao X (2017) Knockdown of Angiopoietin-Like Protein 2 Ameliorates Diabetic Nephropathy by Inhibiting TLR4. Cell Physiol Biochem 43:685-696. doi: $10.1159 / 000480654$

25. El-Asrar MA, Elbarbary NS, Ismail EA and Bakr AA (2016) Circulating angiopoietin-2 levels in children and adolescents with type 1 diabetes mellitus: relation to carotid and aortic intima-media thickness. Angiogenesis 19:421-31. doi: 10.1007/s10456-016-9517-6

26. Persson F, Lindhardt M, Rossing P and Parving HH (2016) Prevention of microalbuminuria using early intervention with renin-angiotensin system inhibitors in patients with type 2 diabetes: $A$ systematic review. J Renin Angiotensin Aldosterone Syst 17. doi: 10.1177/1470320316652047

27. Trietley GS, Wilson SA, Chaudhri P, Payette N, Higbea A and Nashelsky J (2017) Clinical Inquiry: Do ACE inhibitors or ARBs help prevent kidney disease in patients with diabetes and normal BP? J Fam Pract 66:257-263.

28. Group NS, McMurray JJ, Holman RR, Haffner SM, Bethel MA, Holzhauer B, Hua TA, Belenkov Y, Boolell M, Buse JB, Buckley BM, Chacra AR, Chiang FT, Charbonnel B, Chow CC, Davies MJ, Deedwania P, Diem P, Einhorn D, Fonseca V, Fulcher GR, Gaciong Z, Gaztambide S, Giles T, Horton E, Ilkova H, Jenssen T, Kahn SE, Krum H, Laakso M, Leiter LA, Levitt NS, Mareev V, Martinez F, Masson C, Mazzone T, Meaney E, Nesto R, Pan C, Prager R, Raptis SA, Rutten GE, Sandstroem H, Schaper F, Scheen A, Schmitz O, Sinay I, Soska V, Stender S, Tamas G, Tognoni G, Tuomilehto J, Villamil AS, Vozar $\mathrm{J}$ and Califf RM (2010) Effect of valsartan on the incidence of diabetes and cardiovascular events. N Engl J Med 362:1477-90. doi: 10.1056/NEJMoa1001121

29. Currie G, Bethel MA, Holzhauer B, Haffner SM, Holman RR and McMurray JJV (2017) Effect of valsartan on kidney outcomes in people with impaired glucose tolerance. Diabetes Obes Metab 19:791-799. doi: 10.1111/dom.12877

30. Katayama S, Yagi S, Yamamoto H, Yamaguchi M, Izumida T, Noguchi Y, Inaba M and Inukai K (2007) Is renoprotection by angiotensin receptor blocker dependent on blood pressure?: the Saitama Medical School, Albuminuria Reduction in Diabetics with Valsartan (STAR) study. Hypertens Res 30:529-33. doi: 10.1291/hypres.30.529

31. Lyle AN and Taylor WR (2019) The pathophysiological basis of vascular disease. Lab Invest 99:284289. doi: 10.1038/s41374-019-0192-2

32. Tawfik MK and Makary S (2017) 5-HT7 receptor antagonism (SB-269970) attenuates bleomycininduced pulmonary fibrosis in rats via downregulating oxidative burden and inflammatory cascades and ameliorating collagen deposition: Comparison to terguride. European journal of pharmacology 814:114-123. 
33. Tawfik MK (2012) Renoprotective activity of telmisartan versus pioglitazone on ischemia/reperfusion induced renal damage in diabetic rats. Eur Rev Med Pharmacol Sci 16:600-9.

34. Tesch GH and Allen TJ (2007) Rodent models of streptozotocin-induced diabetic nephropathy. Nephrology (Carlton) 12:261-6. doi: 10.1111/j.1440-1797.2007.00796.x

35. Zhou SJ, Bai L, Lv L, Chen R, Li CJ, Liu XY, Yu DM and Yu P (2014) Liraglutide ameliorates renal injury in streptozotocininduced diabetic rats by activating endothelial nitric oxide synthase activity via the downregulation of the nuclear factorkappaB pathway. Mol Med Rep 10:2587-94. doi: 10.3892/mmr.2014.2555

36. Masoad RE, Ewais MM, Tawfik MK and Abd El-All HS (2012) Effect omononuclear cells versus pioglitazone on streptozotocin-induced diabetic nephropathy in rats. Pharmacol Rep 64:1223-33.

37. Saleh S, El-Maraghy N, Reda E and Barakat W (2014) Modulation of diabetes and dyslipidemia in diabetic insulin-resistant rats by mangiferin: role of adiponectin and TNF-alpha. An Acad Bras Cienc 86:1935-48. doi: 10.1590/0001-3765201420140212

38. Kurtz TW, Griffin KA, Bidani AK, Davisson RL, Hall JE, Subcommittee of $P$ and Public Education of the American Heart Association Council on High Blood Pressure R (2005) Recommendations for blood pressure measurement in humans and experimental animals: part 2: blood pressure measurement in experimental animals: a statement for professionals from the Subcommittee of Professional and Public Education of the American Heart Association Council on High Blood Pressure Research. Arterioscler Thromb Vasc Biol 25:e22-33. doi: 10.1161/01.ATV.0000158419.98675.d7

39. Castoldi G, di Gioia CR, Bombardi C, Maestroni S, Carletti R, Steckelings UM, Dahlof B, Unger T, Zerbini G and Stella A (2014) Prevention of diabetic nephropathy by compound 21, selective agonist of angiotensin type 2 receptors, in Zucker diabetic fatty rats. Am J Physiol Renal Physiol 307:F112331. doi: 10.1152/ajprenal.00247.2014

40. Makary S, Abdo M and Fekry E (2017) Oxidative stress burden inhibits spermatogenesis in adult male rats: testosterone protective effect. Canadian journal of physiology and pharmacology.

41. Ndisang JF and Jadhav A (2014) Hemin therapy improves kidney function in male streptozotocininduced diabetic rats: role of the heme oxygenase/atrial natriuretic peptide/adiponectin axis. Endocrinology 155:215-29. doi: 10.1210/en.2013-1050

42. Sun H, Zheng JM, Chen S, Zeng CH, Liu ZH and Li LS (2007) Enhanced expression of ANGPTL2 in the microvascular lesions of diabetic glomerulopathy. Nephron Exp Nephrol 105:e117-23. doi: $10.1159 / 000100493$

43. Elshaer RE, Tawfik MK, Nosseir N, El-Ghaiesh SH, Toraih EA, Elsherbiny NM and Zaitone SA (2019) Leflunomide-induced liver injury in mice: Involvement of TLR4 mediated activation of PI3K/mTOR/NFkappaB pathway. Life Sci 235:116824. doi: 10.1016/j.Ifs.2019.116824

44. Tawfik MK, El-Kherbetawy MK and Makary S (2018) Cardioprotective and Anti-Aggregatory Effects of Levosimendan on Isoproterenol-Induced Myocardial Injury in High-Fat-Fed Rats Involves Modulation of PI3K/Akt/mTOR Signaling Pathway and Inhibition of Apoptosis: Comparison to Cilostazol. J Cardiovasc Pharmacol Ther 23:456-471. doi: 10.1177/1074248418763957 
45. Elbe H, Vardi N, Esrefoglu M, Ates B, Yologlu S and Taskapan C (2015) Amelioration of streptozotocin-induced diabetic nephropathy by melatonin, quercetin, and resveratrol in rats. Hum Exp Toxicol 34:100-13. doi: 10.1177/0960327114531995

46. Ishii T, Furuya F, Takahashi K, Shikata M, Takamura T, Kobayashi H, Miyazaki A, Morinaga J, Terada K, Oike Y, Kanda E and Kitamura K (2019) Angiopoietin-Like Protein 2 Promotes the Progression of Diabetic Kidney Disease. J Clin Endocrinol Metab 104:172-180. doi: 10.1210/jc.2017-02705

47. Nishi H (2016) Angiopoietin-like protein 2 and kidney fibrosis: lessons from knockout mice. Kidney Int 89:272-4. doi: 10.1016/j.kint.2015.12.022

48. Morinaga J, Kadomatsu T, Miyata K, Endo M, Terada K, Tian Z, Sugizaki T, Tanigawa H, Zhao J, Zhu S, Sato M, Araki K, lyama K, Tomita K, Mukoyama M, Tomita K, Kitamura K and Oike Y (2016) Angiopoietin-like protein 2 increases renal fibrosis by accelerating transforming growth factor-beta signaling in chronic kidney disease. Kidney Int 89:327-41. doi: 10.1016/j.kint.2015.12.021

49. Pozzi A and Zent R (2013) Integrins in kidney disease. J Am Soc Nephrol 24:1034-9. doi: 10.1681/ASN.2013010012

50. Niu H, Nie L, Liu M, Chi Y, Zhang T and Li Y (2014) Benazepril affects integrin-linked kinase and smooth muscle alpha-actin expression in diabetic rat glomerulus and cultured mesangial cells. BMC Nephrol 15:135. doi: 10.1186/1471-2369-15-135

51. Kojima N, Williams JM, Slaughter TN, Kato S, Takahashi T, Miyata N and Roman RJ (2015) Renoprotective effects of combined SGLT2 and ACE inhibitor therapy in diabetic Dahl S rats. Physiol Rep 3. doi: 10.14814/phy2.12436

52. Mohamed HE, Asker ME, Keshawy MM, Hasan RA and Mahmoud YK (2020) Inhibition of tumor necrosis factor-alpha enhanced the antifibrotic effect of empagliflozin in an animal model with renal insulin resistance. Mol Cell Biochem. doi: 10.1007/s11010-020-03686-x

53. Carmines PK (2010) The renal vascular response to diabetes. Curr Opin Nephrol Hypertens 19:85-90. doi: 10.1097/MNH.0b013e32833240fc

54. Gilbert RE, Zhang Y, Williams SJ, Zammit SC, Stapleton DI, Cox AJ, Krum H, Langham R and Kelly DJ (2012) A purpose-synthesised anti-fibrotic agent attenuates experimental kidney diseases in the rat. PLoS One 7:e47160. doi: 10.1371/journal.pone.0047160

55. Bunag RD, Tomita T and Sasaki S (1982) Streptozotocin diabetic rats are hypertensive despite reduced hypothalamic responsiveness. Hypertension 4:556-65.

56. Brooks DP, Nutting DF, Crofton JT and Share L (1989) Vasopressin in rats with genetic and streptozocin-induced diabetes. Diabetes 38:54-7. doi: 10.2337/diab.38.1.54

57. Gagliardini E, Perico N, Rizzo P, Buelli S, Longaretti L, Perico L, Tomasoni S, Zoja C, Macconi D, Morigi M, Remuzzi G and Benigni A (2013) Angiotensin Il contributes to diabetic renal dysfunction in rodents and humans via Notch1/Snail pathway. Am J Pathol 183:119-30. doi:

10.1016/j.ajpath.2013.03.025

58. Cooper ME, Mundel P and Boner G (2002) Role of nephrin in renal disease including diabetic nephropathy. Semin Nephrol 22:393-8. doi: 10.1053/snep.2002.34724 
59. Kobori H, Nangaku M, Navar LG and Nishiyama A (2007) The intrarenal renin-angiotensin system: from physiology to the pathobiology of hypertension and kidney disease. Pharmacol Rev 59:251-87. doi: 10.1124/pr.59.3.3

60. Liu T, Zhang L, Joo D and Sun SC (2017) NF-kappaB signaling in inflammation. Signal Transduct Target Ther 2. doi: 10.1038/sigtrans.2017.23

61. Wang W, Qiu L, Howard A, Solis N, Li C, Wang X, Kopp JB and Levi M (2014) Protective effects of aliskiren and valsartan in mice with diabetic nephropathy. J Renin Angiotensin Aldosterone Syst 15:384-95. doi: 10.1177/1470320313507123

62. Wang S, Li Y, Miao W, Zhao H, Zhang F, Liu N, Su G and Cai X (2016) Angiopoietin-like protein 2 expression is suppressed by angiotensin II via the angiotensin II type 1 receptor in rat cardiomyocytes. Mol Med Rep 14:2607-13. doi: 10.3892/mmr.2016.5544

\section{Figures}

\section{Image not available with this version}

\section{Figure 1}

Scheme showing experimental protocols employed. Diabetes mellitus induction by streptozotocin (STZ) was injected intraperitoneal as a single dose $(50 \mathrm{mg} / \mathrm{kg})$ on day (0). Valsartan was given orally daily at dose of $30 \mathrm{mg} / \mathrm{Kg}$. Pharmacological regimen was administered from the $2 \mathrm{nd}$ week, and rats were sacrificed after 4th, 8th and 12th weeks after treatment.

\section{Image not available with this version}


Figure 2

Renoprotective and renotherapeutic effect of valsartan on urinary (a: nephrin "ng/ml", b: KIM-1 "pg/ml") in STZ- induced diabetic nephropathy. Values are mean \pm S.D. $(n=6-8)$, analyzed by one-way ANOVA followed by Tukey's multiple comparisons test. $\mathbf{9},{ }^{\star}, \#, \$ \mathrm{P}<0.05$; 9 compared with vehicle group, * compared with diabetic control group at the same time point,\# compared with diabetic control group at week 4 , \$ compared with diabetic control group at week 8 .

\section{Image not available with this version}

\section{Figure 3}

Renoprotective effect of valsartan on renal gene expression of (RT-PCR; a: NF-KB, b: ANGPTL2, c: TLR 4, d: integrin) in STZ- induced diabetic nephropathy. Values are mean \pm S.D. $(n=6-8)$, analyzed by one-way ANOVA followed by Tukey's multiple comparisons test. $9,{ }^{*}, \#, P<0.05$; 9 compared with vehicle group, * compared with diabetic control group at the same time point,\# compared with diabetic control group at week 4. Angiopoietin-like protein 2 (ANGPTL2), and toll-like receptor 4 (TLR 4), NF-kB (nuclear factor kappa-light-chain-enhancer of activated B cells).

\section{Image not available with this version}

\section{Figure 4}

Renoprotective effect of valsartan on renal protein expression (ELISA; a: angiotensin II "pg/ml protein", b: TGF- $\beta$ “ng/ml protein", c: collagen IV “ng/ml protein") in STZ- induced diabetic nephropathy. Values are mean \pm S.D. $(n=6-8)$, analyzed by one-way ANOVA followed by Tukey's multiple comparisons test. $\mathbf{q},{ }^{\star}, \#, \$$ 
$\mathrm{P}<0.05$; 9 compared with vehicle group, ${ }^{*}$ compared with diabetic control group at the same time point,\# compared with diabetic control group at week 4 , \$ compared with diabetic control group at week 8 .

\section{Fig. 5}

ASMA

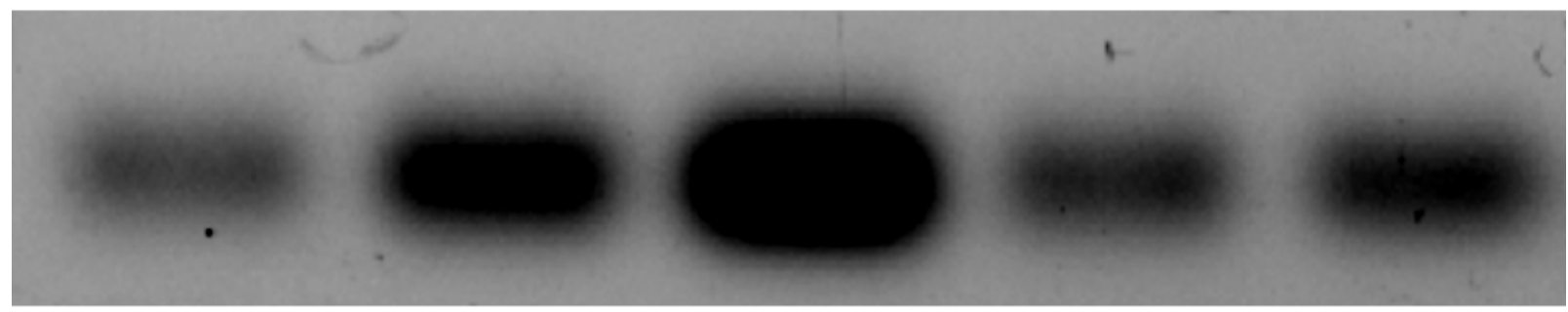

\section{Collagen IV}

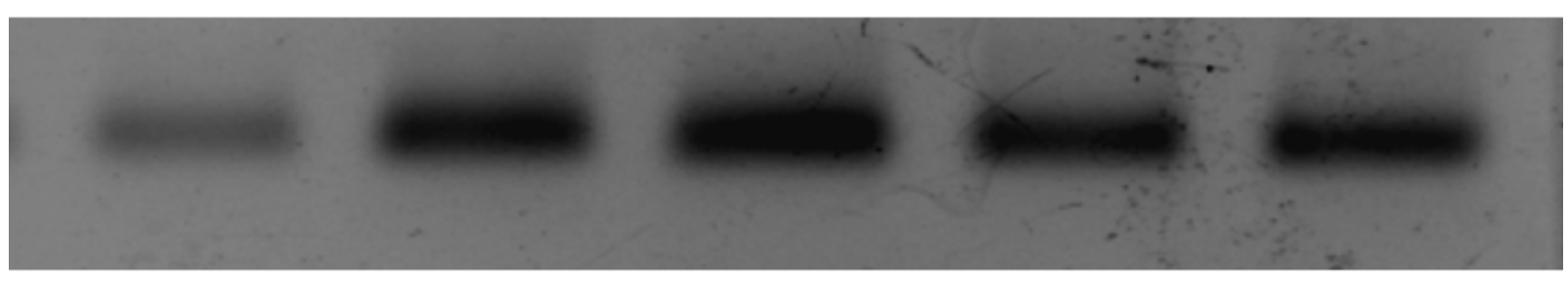

\section{$\beta$ Actin}

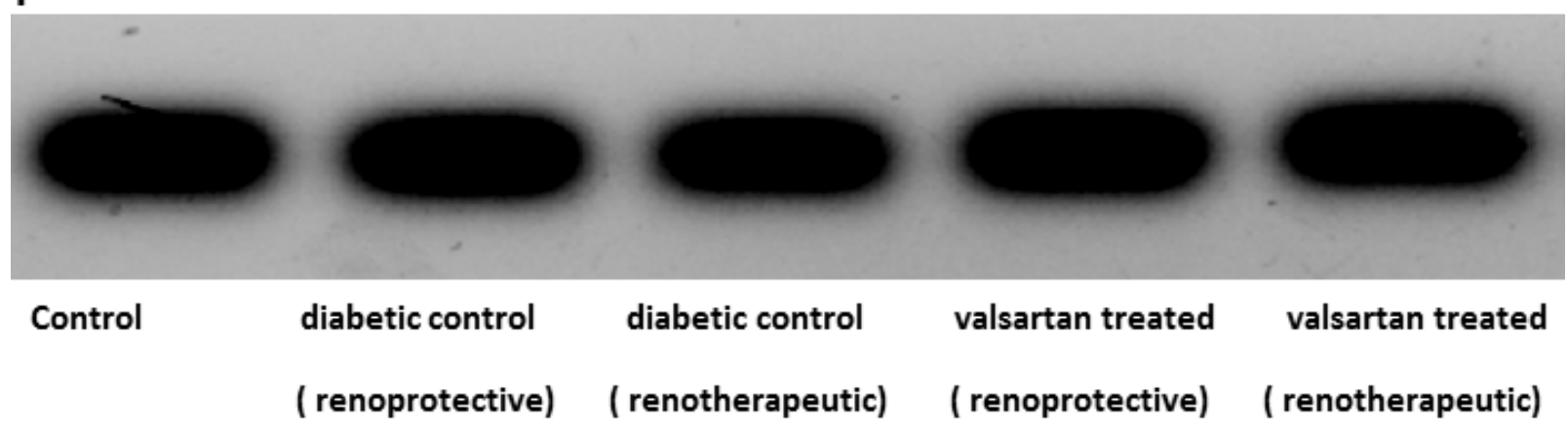

a

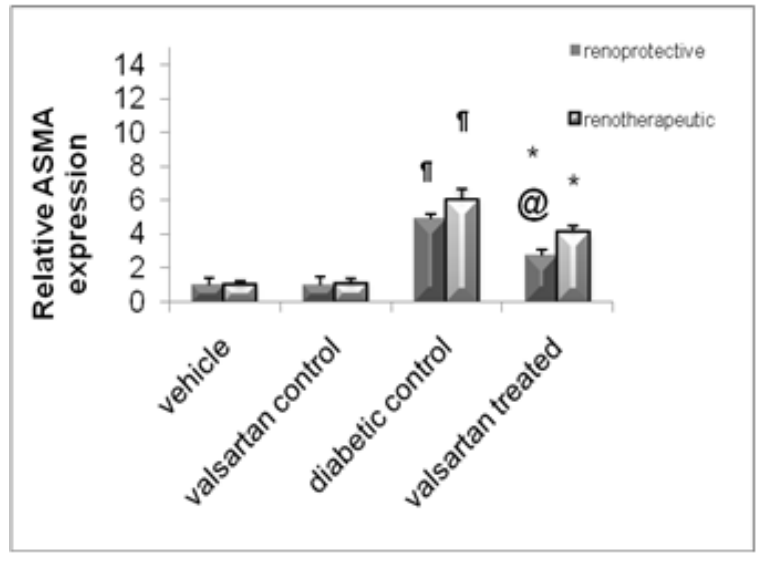

b

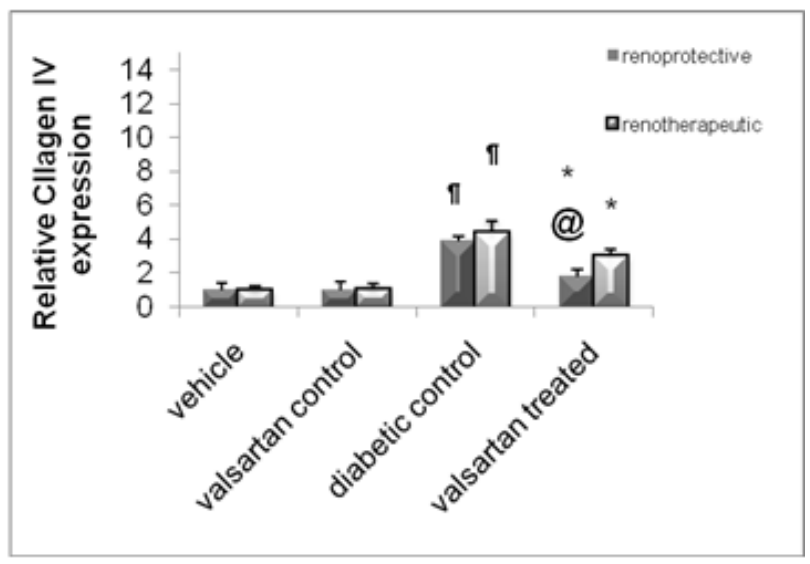

Figure 5

Renoprotective and renotherapeutic effect of valsartan on the relative renal expression of (western blot; a: ASMA, b: Collagen IV) in STZ- induced diabetic nephropathy. Values are mean \pm S.D. $(n=6-8)$, analyzed by one-way ANOVA followed by Tukey's multiple comparisons test. 9, ${ }^{\star}$, @ P< 0.05; 9 compared with vehicle 
group, * compared with diabetic control group at the same time point, @ compared with valsartan treated group "renotherapeutic". Alpha smooth muscle actin (ASMA).

Fig. 6
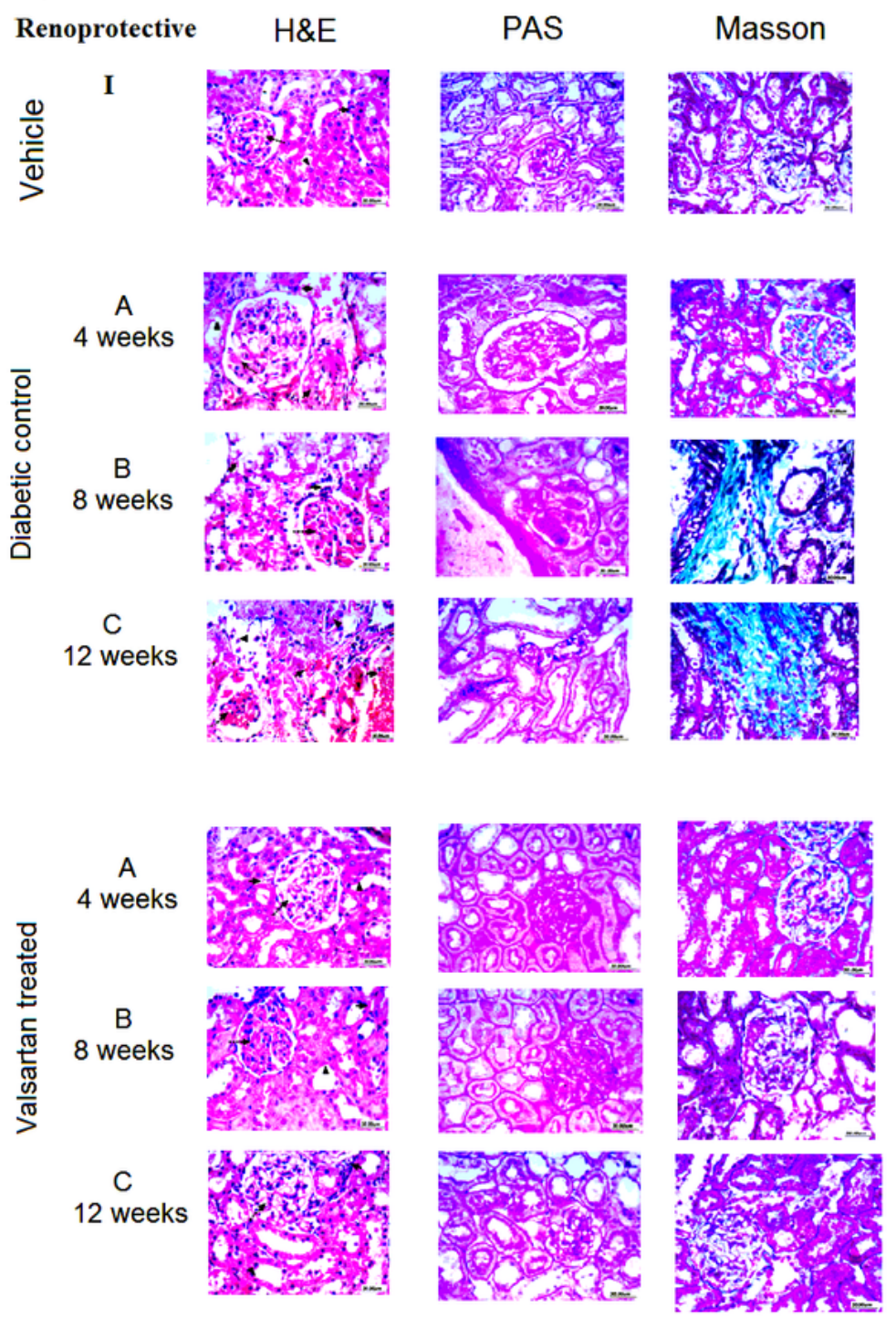

II

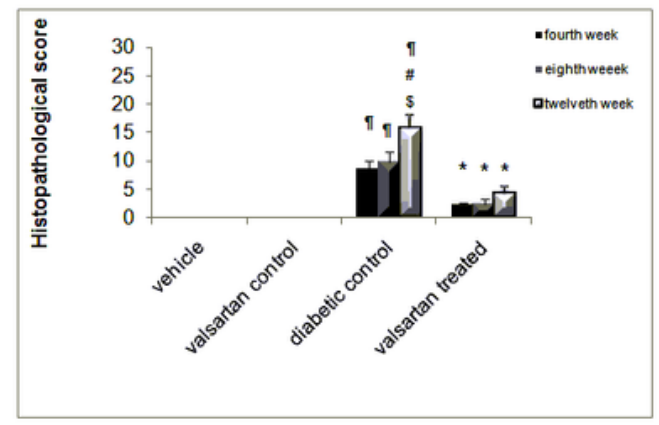

\section{Figure 6}

(I): Photomicrographs of renal tissue using renoprotective regime. Vehicle group showed normal appearance in hematoxylin-eosin (H\&E, left); periodic acid Schiff (PAS, middle); Masson (right), glomeruli (dashed arrow), tubules (arrowhead), intesrtitium (arrow). Diabetic control group after four weeks (A) H\&E 
showed marked congested thick-walled vessels, PAS showed thickening of basement membrane. At eight weeks (B) H\&E showed moderate glomerular congestion, PAS showed glomerular sclerosis. At twelve weeks (C) PAS shows markedly glomeruli with pronounced focal sclerosis affecting $\geq 75 \%$ of surface. The renoprotective effect of valsartan after 4, 8, 12 weeks showed restored brush border improving fibrosis and minimal glomerular sclerosis (H\&E, PAS, Masson $400 \times$ ). (II): Renoprotective effect of valsartan on the renal histopathological score in STZ-induced diabetic nephropathy. Values are mean \pm S.D. ( $n=6-8)$, analyzed by one-way ANOVA followed by Tukey's multiple comparisons test. $9, \star, \#, \$ P<0.05$; I compared with vehicle group, * compared with diabetic control group at the same time point,\# compared with diabetic control group at week 4 , \$ compared with diabetic control group at week 8 . 
Fig. 7

\section{Renotherapeutic}
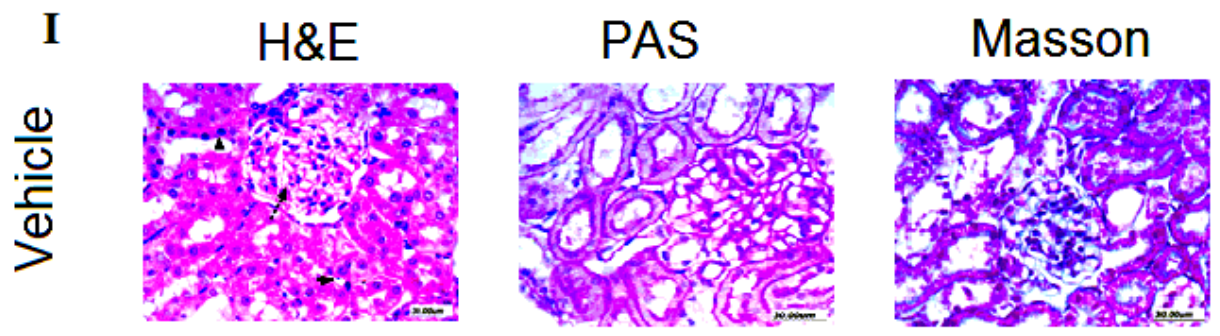

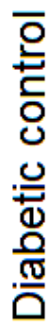
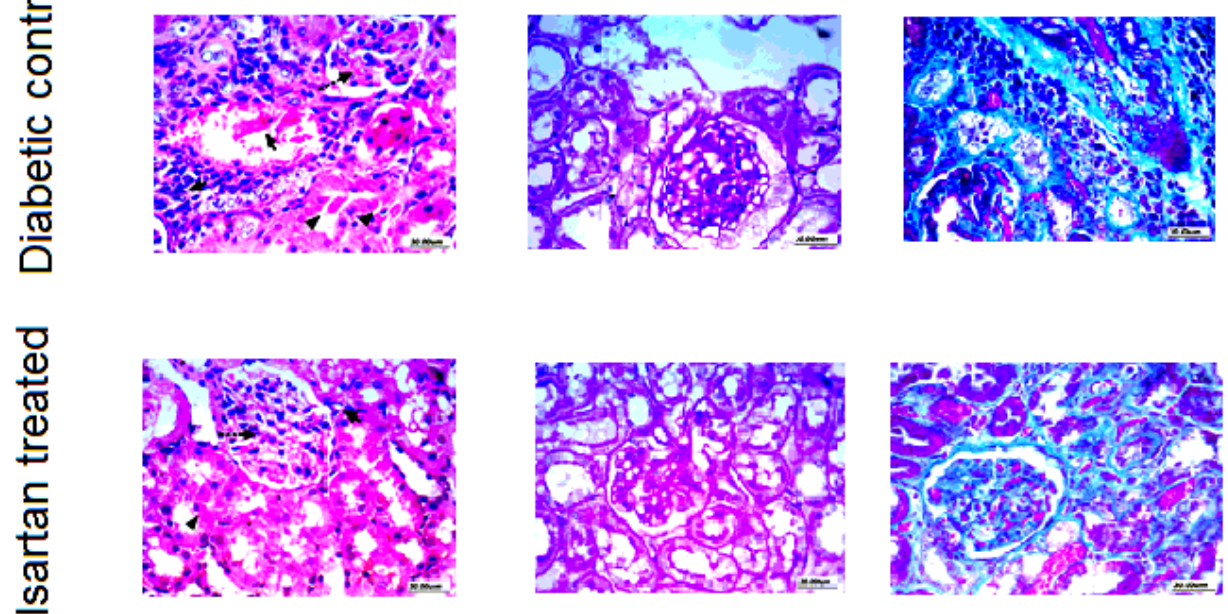

II

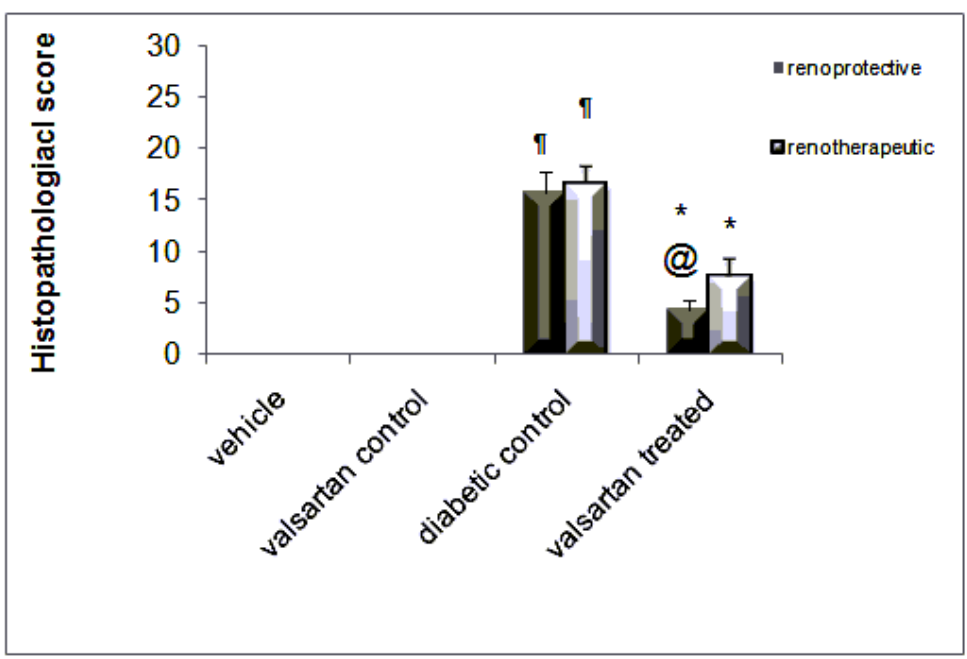

\section{Figure 7}

(I): Photomicrographs comparing renoprotective and renotherepeutic valsartan effect, in which vehicle group showed normal architecture. Renal tissues in the diabetic control group showed congested thickwalled, tubular epithelial cells showed desquamation, glomeruli focal sclerosis affecting $\geq 75 \%$ of surface. Masson showed marked peritubular fibrosis. PAS showed loss of brush border and glomerular sclerosis. Valsartan treated group showed moderate decrease of fibrosis, vascular changes and the 
glomeruli sclerosis. PAS showed residual focal brush border loss with minimal vacuolation. Masson showed improved fibrosis(H\&E, PAS, Masson $400 \times$ ). (II): Renotherapeutic effect of valsartan on the renal histopathological score in STZ- induced diabetic nephropathy. Values are mean \pm S.D. $(n=6-8)$, analyzed by one-way ANOVA followed by Tukey's multiple comparisons test. $9, \star$, @ $\mathrm{P}<0.05$; 9 compared with vehicle group, ${ }^{*}$ compared with diabetic control group, @ compared with valsartan treated group "renotherapeutic".

Fig. 8
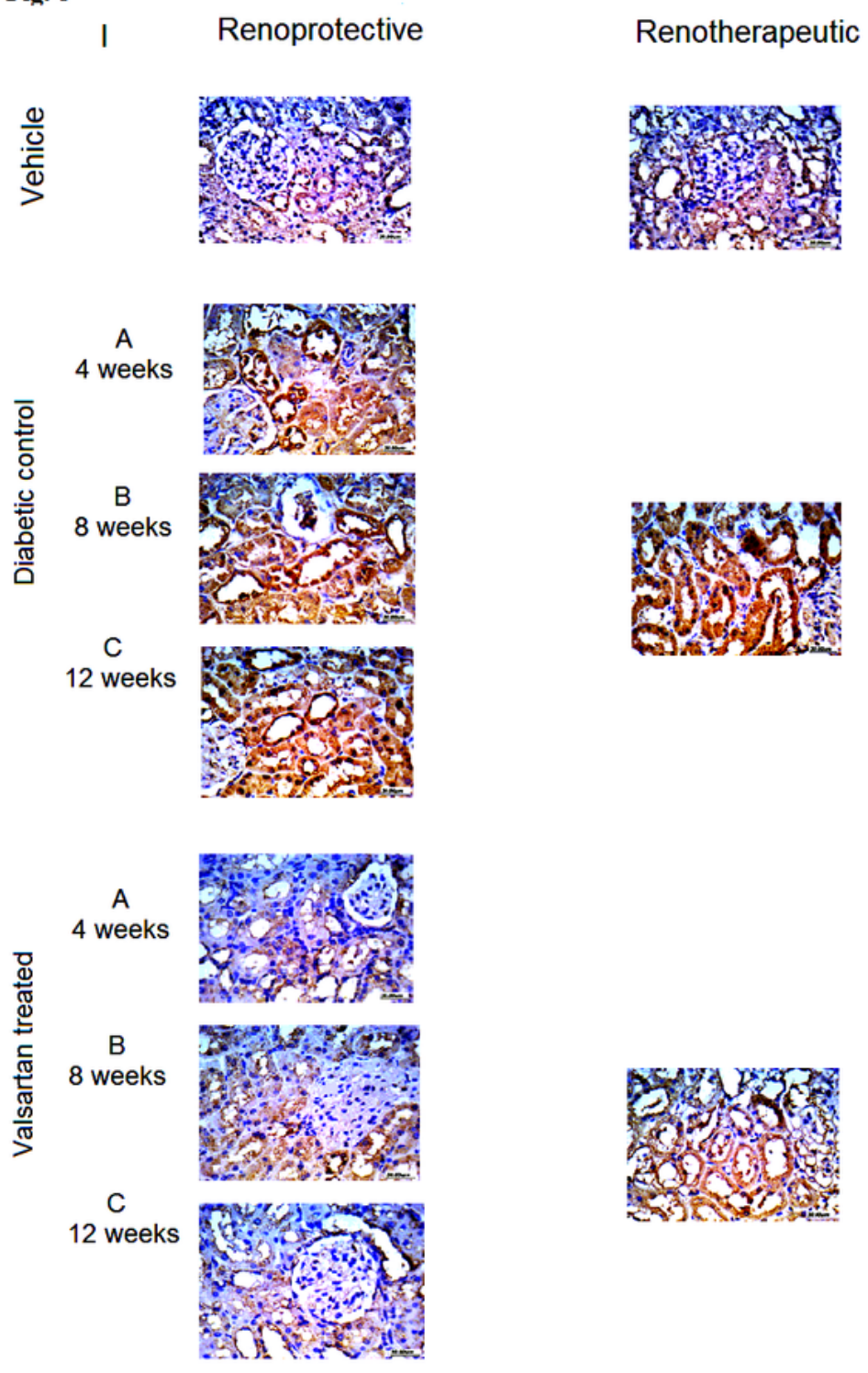

II
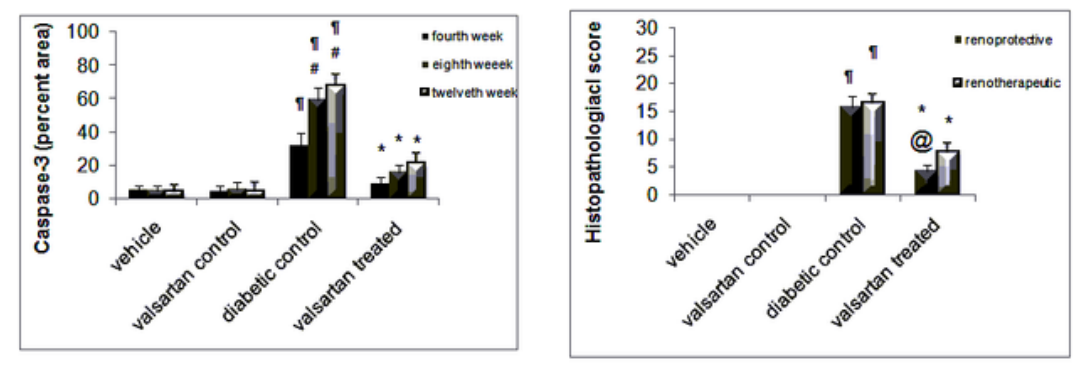

Figure 8 
(I): Photomicrographs sections in renal tissue represent the intensity of caspase- 3 protein expression in different groups in both renoprotective and renptherepeutic regimes (400 x). (II): Renoprotective and renotherapeutic effect of valsartan on the renal expression percentage of the caspase-3 protein in STZinduced diabetic nephropathy. Values are mean \pm S.D. $(n=6-8)$, analyzed by one-way ANOVA followed by Tukey's multiple comparisons test. $\mathbf{9},{ }^{\star}, \#$, @ P< 0.05; 9 compared with vehicle group, * compared with diabetic control group at the same time point,\# compared with diabetic control group at week 4, @ compared with valsartan treated group "renotherapeutic".

\section{Supplementary Files}

This is a list of supplementary files associated with this preprint. Click to download.

- Supplementary.docx 